\title{
Obstáculos prácticos, políticos y administrativos para la profesionalización de las policías municipales mexicanas
}

\author{
Practical, Political and Administrative Obstacles to \\ Professionalization of Mexican Local Police \\ José Manuel Heredia González* \\ Investigador independiente \\ https://orcid.org/oooo-0002-9777-0452
}

ISSN-OI85-4259; e- ISSN: 2007-9I76 DoI: http://dx.doi.org/IO.28928/ri/90202I/atc4/herediagonzalezj

\section{Resumen}

En México desde 2007 la profesionalización de las corporaciones locales de policía se convirtió en una prioridad para los tres niveles de gobierno. En 2008 el Gobierno Federal estableció el Subsidio para la Seguridad en los Municipios (SubSemun) a través del cual entregaron de 2008 a 2015 más de i 600 millones de dólares a los principales municipios del país para fortalecer sus policías locales. Sin embargo, los avances fueron insuficientes y en muchos ayuntamientos se mantuvo o incluso aumentó la desconfianza hacia las policías locales y la incidencia de delitos de alto impacto. Este texto investiga cómo se utilizaron los recursos del subSEMUN en los ayuntamientos y analiza los obstáculos prácticos, políticos y administrativos que se presentaron durante la implementación de las herramientas de profesionalización impulsadas por el subsidio. Con base en los resultados de la investigación se ofrecen algunas reflexiones sobre el diseño de apoyos para las policías locales.

Palabras clave: policía, política pública, profesionalización, gobiernos locales, subsidios

\begin{abstract}
Since 2007, the professionalization of local police departments in Mexico has been a priority for all three levels of government. In 2008, the Federal Government established the Subsidy for Security in the Municipalities (SUBSEMUN), through which it provided more than \$I.6 billion dollars between 2008 and 2015 to the country's largest municipalities to strengthen their local police. However, progress was insufficient, and in many municipalities, the public's distrust of local police and the incidence of high-impact crime remained the same or, in some cases, even increased. This paper investigates how municipalities used SUвSEMUN resources and analyzes the practical, political, and administrative obstacles that arose during the implementation of the professionalization tools promoted by the subsidy. The paper also offers some reflections on the design of subsidies for local police based on the study's findings.
\end{abstract}

Keywords: police, public policy, professionalization, local governments, subsidies

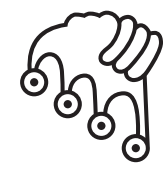

IZTAPALAPA

Agua sobre lajas

* manui97a@gmail.com 
l colmo! Policía municipal y su esposa asaltan Oxxo en Bosques de
Manzanilla; vecinos los golpean", lee el encabezado en un periódico local México, el cual recibió de 2008 a 2015 más de I 300 millones de pesos (alrededor de 65 millones de dólares) a través de un subsidio federal para profesionalizar sus policías locales. Este tipo de noticias se extienden a todo el territorio mexicano, no solamente narrando la participación de policías municipales en activo en asaltos a tiendas de conveniencia, sino además en robo de autos (Campos, 2017; Imagen del Golfo, 2017; El Heraldo de México, 2020), secuestros (Proceso, 2017; Radio Fórmula, 2017; SinEmbargo, 2019), ejecuciones (La Prensa de Monclova, 20I7; 90 grados, 2020), entre otros delitos.

La corrupción de la función del policía local en México no es nueva, sino que se remonta a décadas atrás (Davis, 2006). Debido a esto, comenzando en 1994 se promovieron diversas reformas para contar con una política nacional de combate a la delincuencia, y en 2007 se incorporó la profesionalización de las policías municipales como una prioridad. En ese año se aprobó un nuevo programa de seguridad pública, concertado entre los diferentes niveles de gobierno, como respuesta "a la desconfianza de la población hacia las policías locales, al alza en la incidencia de delitos de alto impacto, y a la falta de eficiencia de los cuerpos de policía" (Cámara de Diputados, 20II).

Como parte de este programa, el Secretariado Ejecutivo del Sistema Nacional de Seguridad Pública (sESNSP), órgano federal responsable de la política de seguridad pública en México, estableció en 2008 el Subsidio para la Seguridad en los Municipios (SUBSEMUN $)^{1}$ con el objetivo de fortalecer y equipar a las policías locales de los municipios más poblados y con mayores índices de criminalidad del país (SESNSP,

1 El nombre del subsidio se cambió en años posteriores a "Subsidio a los Municipios y Demarcaciones Territoriales del Distrito Federal y, en su caso, a las Entidades Federativas que Ejerzan de Manera Directa o Coordinada la Función de Seguridad Pública", pero el SESNSP continuó utilizando las siglas SUBSEMUN. 
$2011){ }^{2}$ De 2008 a 2015 se entregaron apoyos materiales y logísticos a los municipios elegidos para fortalecer aspectos relacionados con la formación policial, el sistema de carrera, el salario de los policías, el equipamiento y los controles de confianza (exámenes para detectar si el policía ha participado en alguna actividad ilegal). Sin embargo, en la mayor parte de los municipios la profesionalización policial continúa siendo un tema pendiente y, en muchos aspectos, con el sUBSEMUN no se consiguió "ningún avance proporcional a los esfuerzos realizados" (Tello, 2013: 307).

¿Por qué no se obtuvieron los resultados esperados con el subSEMUN? La hipótesis de este texto es que en los ocho años que estuvo vigente el subsidio existieron obstáculos clave, tanto prácticos como políticos y administrativos, que retrasaron - o anularon por completo- la política de profesionalización de las policías locales. El texto se divide en cinco secciones. En primer lugar, se describe la organización de las corporaciones municipales en México y los apoyos federales que se han establecido históricamente para fortalecerlas. Se describe también el funcionamiento del subSEMun y la principal herramienta de profesionalización promovida por este subsidio: la Carrera Policial. En segundo lugar, se explica la metodología del texto para recabar y analizar información disponible sobre el subsidio en los municipios mexicanos. En tercero, se presentan los resultados de la investigación. Esta sección se subdivide en cinco subapartados, cada uno dedicado a un obstáculo identificado (predilección por el statu quo, oposición deliberada, dificultad para identificar e implementar herramientas, condiciones culturales y organizacionales, y esfuerzos por reconstruir la reforma). En cuarto lugar, se presentan buenas prácticas identificadas en la literatura para superar cada uno de los cinco obstáculos descritos en el texto. Finalmente, la conclusión.

\section{Corporaciones policiales en los municipios mexicanos y apoyos federales para fortalecerlas}

Desde 1999, el Art. II5 de la Constitución Mexicana otorga a los municipios la facultad exclusiva para ejercer la seguridad pública en su territorio bajo los principios del Art. 2I Constitucional —legalidad, objetividad, eficiencia, profesionalismo, honradez y respeto a los derechos humanos-. Además, se confiere a los municipios

2 A partir de 2016, el subsemun fue sustituido por el Programa Fortalecimiento a la Seguridad (FORTASEG), el cual continúa hasta el día de hoy (2020) con reglas de operación y requisitos para elegibilidad muy distintos al SUBSEMUN. 
la autoridad para "aprobar y modificar los bandos de policía y buen gobierno, los reglamentos, circulares y disposiciones administrativas de observancia general dentro de sus respectivas jurisdicciones." ${ }^{3}$ Así, siempre y cuando sigan los principios constitucionales, cada municipio tiene independencia para definir los procedimientos $y$ políticas relativas a sus corporaciones policiales.

Esta autonomía en la gestión de la seguridad pública municipal ha tenido como consecuencia diferencias importantes en el actuar de las policías locales, así como en sus sistemas de ingreso, desarrollo, evaluación, asenso, sanción y separación (Cámara de Diputados, 20II). Históricamente, los intentos de los propios municipios por profesionalizar a sus policías no han logrado resultados positivos ni de largo plazo, principalmente porque estos esfuerzos son reinventados cada tres años al cambiar la administración después de las elecciones locales (Sabet, 2013). Por consiguiente, en México ha prevalecido un entorno generalizado de poca profesionalización en la seguridad pública local, y permanentemente "la situación de las policías municipales es muy precaria, operan con muchas limitaciones y tienen los mismos vicios estructurales que todas las policías nacionales" (Tello, 2013:295).

En México, las políticas en materia de seguridad pública han sido competencia casi exclusiva del gobierno federal. Las políticas públicas en esta materia, entendidas ampliamente como decisiones para resolver problemas públicos de seguridad y articuladas por medio de acciones y programas con fundamento legal a través de cuerpos administrativos (Aguilar, 1992), son diseñadas principalmente por órganos federales pero implementadas por los gobiernos locales que constitucionalmente son responsables de la seguridad en su territorio. Esta "transferencia" de políticas con grandes objetivos no siempre ha resultado exitosa por las carencias locales, tanto económicas como técnicas y administrativas. Debido a esto y frente a los problemas de las corporaciones locales, el gobierno federal, a través de diversas dependencias como el SESNSP, ha establecido diferentes apoyos para ayudar a mejorar los cuerpos de seguridad pública de los municipios (véase cuadro I). Estos apoyos han tenido como objetivo principal el fortalecimiento de los municipios y los estados con equipamiento, modernización, y la profesionalización administrativa de sus corporaciones policiales (Meyer, 2014).

3 Reforma al Art. II5 constitucional. Diario Oficial de la Federación (23/12/1999); Carbonell (2004). 


\section{Cuadro i.}

Apoyos federales para la seguridad pública en México

\begin{tabular}{llll}
\hline Nombre & Beneficiarios & Objetivos & Periodo \\
\hline Fondo de Seguridad & 32 entidades fede- & Financiamiento de las accio- 1998-20I2 \\
Pública en el Estado & rativas & nes en materia de seguridad \\
(Foseg) & & pública necesarias para el \\
& funcionamiento eficaz del Sis- \\
& tema Nacional de Seguridad \\
& Pública. \\
& http://www.cefp.gob. \\
& mx/notas/20og/nota- \\
& cefpor62009.pdf \\
\hline
\end{tabular}

Fondo de Aportacio- 32 entidades fedenes para la Seguridad rativas y municiPública de los estados pios elegidos por y del Distrito Fede- la entidad ral (hoy Ciudad de México) (FASP)

Subsidio para la Seguridad en los Municipios (SUBSEMUN) equipamiento, mejoramiento

de la infraestructura, establecimiento y operación de la red nacional de telecomunicaciones e informática

Profesionalización policial, 2008-2015 dades federativas equipamiento, mejoramiento que ejercen la fun- de la infraestructura, estableción de seguridad cimiento y operación de la red pública a nivel nacional de telecomunicaciomunicipal nes e informática, desarrollo de políticas públicas para la prevención social del delito

\begin{tabular}{|c|c|c|c|}
\hline $\begin{array}{l}\text { Subsidio a las entida- } \\
\text { des federativas para } \\
\text { el fortalecimiento de } \\
\text { sus instituciones de } \\
\text { seguridad pública en } \\
\text { materia de mando } \\
\text { policial (sPa) }\end{array}$ & $\begin{array}{l}32 \text { entidades fede- } \\
\text { rativas }\end{array}$ & $\begin{array}{l}\text { Profesionalización policial, } \\
\text { establecimiento y operación } \\
\text { de la red nacional de teleco- } \\
\text { municaciones e informática, } \\
\text { desarrollo de políticas públi- } \\
\text { cas para la prevención social } \\
\text { del delito }\end{array}$ & $2011-2015$ \\
\hline $\begin{array}{l}\text { Subsidio de apoyos } \\
\text { a las entidades fede- } \\
\text { rativas en materia } \\
\text { de seguridad pública } \\
\text { (PROASP) }\end{array}$ & $\begin{array}{l}32 \text { entidades fede- } \\
\text { rativas }\end{array}$ & $\begin{array}{l}\text { Desarrollo de políticas públi- } \\
\text { cas para reducir los índices } \\
\text { delictivos de los delitos de } \\
\text { mayor impacto social }\end{array}$ & 2012 \\
\hline
\end{tabular}




\begin{tabular}{llll}
\hline Nombre & Beneficiarios & Objetivos & Periodo \\
\hline Programa Fortaleci- & Municipios y enti- & Profesionalización policial, 20I6- \\
miento a la Seguridad & dades federativas & equipamiento, formación con- \\
(FORTASEG) & que ejercen la fun- & tinua en materia de Sistema \\
& ción de seguridad & de Justicia Penal Acusatorio, \\
& pública a nivel & construcción de infraestruc- \\
& municipal & tura
\end{tabular}

Fuente: elaboración propia con base en documentación del SESNSP y Delgado (2012).

Dentro de estos apoyos federales se enmarca el subSEMun. Este subsidio tuvo el objetivo de fortalecer y equipar a las policías locales de los municipios más poblados y con mayores índices de criminalidad del país. Cada año-de 2008 hasta 2015 - se ministraron recursos federalizados con base en una fórmula que identificaba a los municipios elegibles. ${ }^{4}$

Cuando un ayuntamiento era elegido para recibir el subsidio, al inicio del año se firmaba un convenio específico de adhesión que establecía el monto del SUBSEMUN y los compromisos que adquirían los municipios con el SESNSP, principalmente el envío de reportes sobre la implementación de herramientas de profesionalización en las corporaciones municipales. Estos compromisos se modificaban de acuerdo con los objetivos prioritarios del subsidio de cada año. Para realizar estas acciones, los municipios contaban con apoyo logístico y administrativo de la SESNSP. La colaboración entre los gobiernos locales y el federal tenía base en la Ley General del Sistema Nacional de Seguridad Pública (LGSNSP), aprobada por el Congreso en 2009, la cual establece las bases de coordinación entre diferentes organizaciones públicas de seguridad.

Uno de los objetivos principales del suBSEMUN, que se mantuvo vigente durante todo el subsidio y que fue la herramienta principal de profesionalización, fue el establecimiento de la Carrera Policial en los municipios beneficiarios. Esta carrera está establecida en el título quinto de la LGSNSP y es definida como

el sistema de carácter obligatorio y permanente, conforme al cual se establecen los lineamientos que definen los procedimientos de reclutamiento, selección, ingreso,

4 La fórmula de elegibilidad consideraba seis criterios: (I) población del municipio, (2) incidencia delictiva en delitos de alto impacto (como homicidio y secuestro), (3) turismo, (4) si el municipio se encontraba en una zona fronteriza, (5) si era un municipio conurbado y (6) la proximidad geográfica con otros municipios de alta incidencia delictiva. 
formación, certificación, permanencia, evaluación, promoción y reconocimiento; así como la separación o baja del servicio de los integrantes de las Instituciones Policiales (Art. 78)

La carrera policial tiene el objetivo de promover valores como la equidad, la responsabilidad, la honradez, la eficiencia y la eficacia en el desempeño de las funciones (Art. 79). También busca desarrollar la vocación de servicio y el sentido de pertenencia de los integrantes de las instituciones policiales por medio del desarrollo profesional, la capacitación y la profesionalización permanentes (Art. 79). En la práctica, este servicio de carrera se traduce en un sistema de puntos que regula los mecanismos de ingreso, promoción y separación. Estos puntos son ganados a través del mérito policial, las evaluaciones de desempeño de la función, las competencias laborales, el desarrollo profesional (capacitación) y la antigüedad (ASF, 2008, t. X, vol. 20).

Para lograr los objetivos planteados en el convenio de adhesión, la federación se comprometió a entregar recursos federales a los municipios, mientras que los ayuntamientos se comprometían a aportar un 30\% adicional. El número de municipios beneficiados y el monto total etiquetado para este objetivo variaron de forma importante durante los años en que se entregó el subsidio (véase gráfico I). Mientras que en 2008 el subsidio se entregó a I 49 municipios y se erogaron 3580 millones de pesos (alrededor de 180 millones de dólares), en 2015 el subsidio se entregó a 280 municipios y se erogaron 3968 millones de pesos (cerca de 200 millones de dólares). Estas variaciones en el número de municipios beneficiados y montos dedicados al subsidio afectaron de forma importante el impacto del subsemun. 


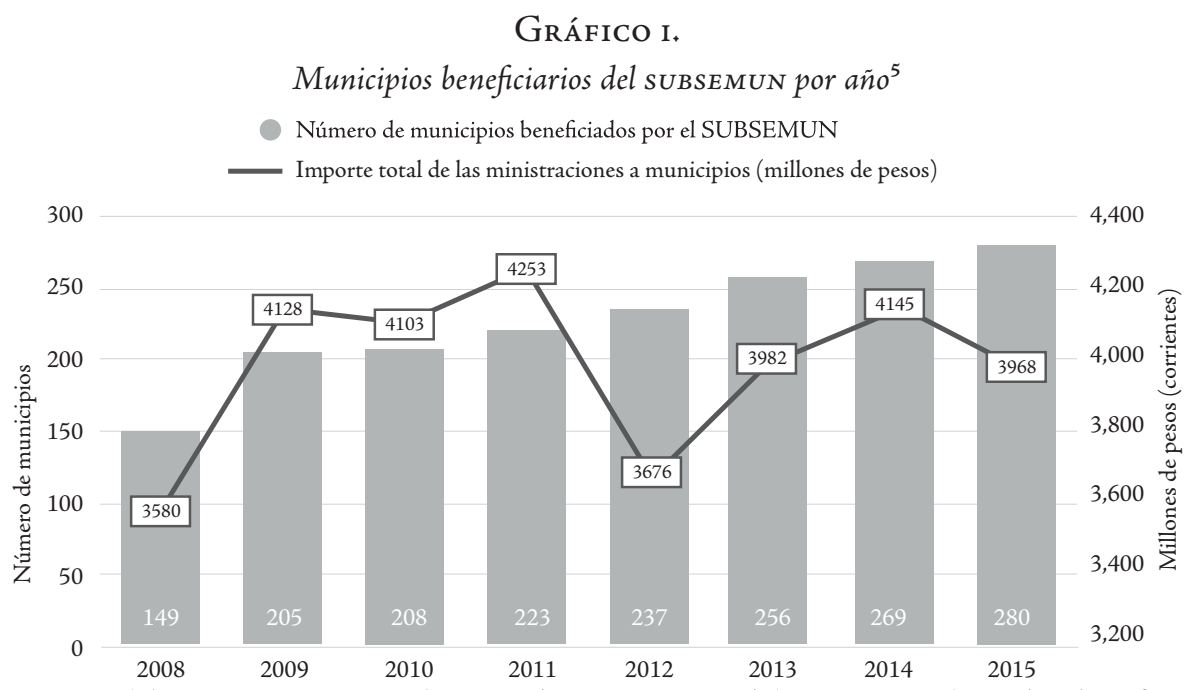

Fuente: elaboración propia con base en documentación del SESNSP y solicitudes de información pública.

En total, de 2008 a 2015 se benefició a 301 ayuntamientos, algunos de los cuales recibieron el subsidio una sola vez -20 ayuntamientos-, mientras que otros recibieron el apoyo todos los años - I42 municipios- (véase cuadro 2). Es importante resaltar que $80 \%$ de los ayuntamientos recibió el subsidio durante cuatro o más años, asegurando que hubo al menos un cambio de edil y cabildo después de las elecciones locales (las cuales se realizan cada tres años).

\section{Cuadro 2.}

Número de veces que los municipios fueron beneficiarios SUBSEMUN

\begin{tabular}{lccccccccc}
\hline Cantidad & 1 & 2 & 3 & 4 & 5 & 6 & 7 & 8 & Total \\
\hline Núm. municipios & 20 & 17 & 24 & 23 & 16 & 20 & 39 & 142 & 301 \\
\hline Porcentaje & 7 & 6 & 8 & 8 & 5 & 7 & 13 & 47 & 100
\end{tabular}

Fuente: elaboración propia con base en documentación del SESNSP y solicitudes de información pública.

5 Los datos consideran los recursos ministrados a precios corrientes; no se incluye coparticipación municipal (equivalente a 30\% de la aportación federal) ni las aportaciones federales a los gobiernos estatales. Tampoco se incluyen las ministraciones declinadas por los municipios ni las ministraciones canceladas. 


\section{Metodología de investigación}

Para conocer el impacto del subSEMUn en el proceso de profesionalización policial de los municipios beneficiarios se revisaron diversas fuentes: I) leyes y documentos relativos al subsidio, incluyendo las reglas de operación, los manuales de procedimientos, las circulares informativas a los municipios, los convenios de adhesión y los informes de resultados publicados por el SESNSP; 2) auditorías realizadas por la Auditoría Superior de la Federación (ASF) a la administración de los recursos del subsidio (disponibles para los años 2008 a 2015); $\left.{ }^{6} 3\right) 3220$ solicitudes de información históricas que recibió el SESNSP de 2008 a 2015 por medio del sistema de transparencia por internet INFOMEX (véase cuadro 3). Además, se realizaron diversas solicitudes de información pública adicionales al SESNSP.

\section{Cuadro 3.}

Municipios beneficiarios del SUBSEMUN, auditorias realizadas por la ASF $y$ solicitudes de información (SESNSP) - sistema INFOMEX

\begin{tabular}{lcccccccc}
\hline Año & 2008 & 2009 & 2010 & 2011 & 2012 & 2013 & 2014 & 2015 \\
\hline $\begin{array}{l}\text { Número de municipios } \\
\text { beneficiarios }\end{array}$ & 149 & 205 & 208 & 223 & 237 & 256 & 269 & 280 \\
\hline $\begin{array}{l}\text { Número de municipios } \\
\text { auditados por la ASF }\end{array}$ & II & I5 & 20 & $29^{*}$ & 24 & $86^{*}$ & $110^{*}$ & $70^{*}$ \\
\hline $\begin{array}{l}\text { Solicitudes de información } \\
\text { pública al SESNSP }\end{array}$ & 170 & 231 & 196 & 321 & 394 & 492 & 726 & 690 \\
\hline
\end{tabular}

Fuente: elaboración propia con base en documentos de la ASF e información del sistema Infomex. * Algunas de las auditorías fueron realizadas por las Entidades de Fiscalización Superior de las Legislaturas Locales (EFSL), a solicitud de la ASF.

Dos fuentes adicionales revisadas fueron: 4) evaluaciones al SUBSEMUn encargadas por el Consejo Nacional de Evaluación de la Política de Desarrollo Social (CONEVAL), y 5) una consulta sistemática de noticias en medios de comunicación nacionales y locales sobre el subsidio y las policías municipales.

6 Cada auditoría comprende una muestra de municipios beneficiados, que ha variado cada año entre $7 \%$ y $41 \%$ del total. 
De cada fuente revisada se extrajeron datos empíricos y narrativos; estadísticas oficiales y de organizaciones no gubernamentales; inferencias sobre el estado presente o futuro de la profesionalización policial; resultados de entrevistas y encuestas a funcionarios y policías; opiniones y posturas personales e institucionales. Estos datos se sistematizaron, se analizaron y se agruparon en cinco apartados para describir el avance y los obstáculos enfrentados por los municipios al intentar profesionalizar sus policías.

\section{Los obstáculos para la profesionalización de las policías muni- cipales mexicanas}

Para el cumplimiento cabal del compromiso de profesionalización previsto en el SUbSeMun, los municipios debían realizar las siguientes acciones (SESNSP, 2OII; ASF, 2008, t. X, vol. I): implementación del Servicio Profesional de Carrera Policial; renivelación salarial de acuerdo con el tabulador del Servicio de Carrera; restructuración jerárquica bajo un esquema terciario; ${ }^{7}$ evaluación de control y confianza de todos los elementos de la corporación en activo y por ingresar, ${ }^{8}$ y programación regular de capacitaciones especializadas. ${ }^{9}$

En un inicio estaba estipulado que en un año los municipios beneficiarios deberían: I) implementar la carrera policial; 2) lograr la renivelación salarial y la restructuración jerárquica terciaria; 3 ) programar todas las evaluaciones en los Centros de Evaluación y Control de Confianza (CECC) estatales, y 4) concluir las capacitaciones especializadas de todos los policías de la corporación. Ningún municipio cumplió en ese primer año todos estos compromisos. Además, "[d]e acuerdo con los parámetros de calificación establecidos para la evaluación de los municipios beneficiados con

7 Bajo este esquema terciario, cada célula básica se compone de exactamente tres personas (elementos) dentro de una jerarquía de crecimiento por grado, desde policía hasta inspector general. Así, por ejemplo, en un pelotón un policía segundo tiene bajo su cargo a tres policías terceros, cada uno de los cuales tiene bajo su cargo a tres policías. Esta estructura se repite en las secciones, las compañías, los grupos, hasta las coordinaciones. Estas evaluaciones están a cargo del Centro Nacional de Evaluación, Control y Confianza de la Comisión Nacional de Seguridad (CNs), y se componen de cinco pruebas: (I) psicométricas, (2) toxicológicas, (3) médicas, (4) patrimonial y de entorno social y (5) confianza.

9 Estas capacitaciones incluían: Informe Policial Homologado (IPH), Manual Básico de Actuación Policial y Sistema Único de Información Criminal (suic). 
recursos del SUBSEMUN, en 2008 ninguno de los evaluados superaron la categoría M (Malo)" pues cumplieron con menos de $59 \%$ de las metas establecidas del subsidio para ese año (ASF, 2008, t. IX, vol. 2). A ocho años de comprometerse a realizar todas estas acciones, I0\% de los 301 municipios beneficiarios no había implementado la carrera policial, no llevaron a cabo la renivelación salarial o no reestructuraron la corporación en el esquema jerárquico terciario (véase cuadro 4).

\section{Cuadro 4.}

Cumplimiento de objetivos SUBSEMUN relativos a la profesionalización policial

\begin{tabular}{lll}
\hline Objetivo de profesionalización & $\begin{array}{l}\text { Núm. de municipios } \\
\text { que cumplieron }\end{array}$ & $\begin{array}{l}\text { Núm. de municipios } \\
\text { que no cumplieron }\end{array}$ \\
\hline $\begin{array}{l}\text { Implementación del Servicio Profesional de } \\
\text { Carrera y renivelación salarial }\end{array}$ & $270(89.7 \%)$ & $31(\mathrm{I} 0.3 \%)$ \\
\hline $\begin{array}{l}\text { Reestructuración en el esquema jerárquico } \\
\text { terciario }\end{array}$ & $275(91.4 \%)$ & $26(8.6 \%)$ \\
\hline
\end{tabular}

Fuente: elaboración propia con base en documentación del SESNSP y solicitudes de información pública (corte a marzo 2016).

¿Por qué hubo retrasos en el cumplimiento de los objetivos de profesionalización? La hipótesis de este texto es que existieron obstáculos prácticos, políticos y administrativos que retrasaron la implementación de las herramientas de profesionalización en las policías locales (véase cuadro 5). A continuación se describe cada uno de estos obstáculos con base en la literatura de políticas públicas y la evidencia encontrada en la revisión documental del SUBSEMUN.

\section{Cuadro 5.}

Obstáculos para la profesionalización administrativa de las corporaciones municipales

Obstáculos descritos-literatura Obstáculos identificados en la práctica

I. Predilección por el statu quo + Maquillaje de cifras de incidencia delictiva en municipios

- No adopción de las herramientas de profesionalización y evitación de los costos

2. Oposición deliberada de políticos beneficiados por el sistema de patronazgo

+ Rezago de los cabildos para aprobar el reglamento de policía 


\begin{tabular}{lc}
\hline Obstáculos descritos - literatura & Obstáculos identificados en la práctica \\
\hline $\begin{array}{l}\text { 3. Dificultad para identificar e } \\
\text { instrumentar las herramientas } \\
\text { adecuadas para profesionalizar }\end{array}$ & $\begin{array}{l}\text { Diseño inadecuado del plan de instrumentación de } \\
\text { las herramientas de profesionalización } \\
\text { Evaluación inexacta de los avances de la profesio- } \\
\text { nalización }\end{array}$ \\
\hline $\begin{array}{l}\text { 4. Condiciones culturales y } \\
\text { organizacionales anteriores a } \\
\text { la reforma }\end{array}$ & + Resistencia a cambiar la cultura policial \\
\hline $\begin{array}{l}\text { 5. Esfuerzos para deconstruiry y } \\
\text { reconstruir la reforma }\end{array}$ & + Primacía de objetivos políticos en las propuestas \\
\hline Fuente: elaboración propia & para transformar la reforma de profesionalización \\
\hline
\end{tabular}

\section{Predilección por el statu quo}

Debido a la aversión al riesgo que experimentan los políticos (Weyland, 2008), muchos se oponen a adoptar reformas profundas en la administración pública, aunque esto signifique continuar con un sistema imperfecto propenso a la captura y a la corrupción (BID, 20I4; Merino, 2013). Por esto, es usual "maquillar" cifras, alterar información y ocultar datos (Carreño y López, 2015) que pudieran forzar un cambio. En este sentido hubo dos obstáculos principales en los esfuerzos por profesionalizar las policías locales mexicanas: maquillaje de las cifras de incidencia delictiva y evasión para no adoptar las herramientas de profesionalización.

\section{Maquillaje de cifras de incidencia delictiva en los municipios}

Las cifras de incidencia delictiva utilizadas en México para la planificación de políticas corresponden únicamente a los delitos cometidos que se denuncian, mientras que se omiten los que no son denunciados, los cuales representan más de $90 \%$ del total de ilícitos (Arango y Lara, 2007). Por otra parte, existe una pauta constante del gobierno mexicano para minimizar las cifras y considerar como "casos aislados" los delitos y las violaciones a los derechos humanos que, por cierto, son de una alta incidencia (Cortez, 2016). Debido a este estrecho uso de los datos, "[s]i bien los medios de comunicación a menudo retratan a México como el lugar más peligroso del mundo, estadísticamente es un lugar muy seguro" (Oppenheimer, 2015). Esta minimización estadística de la violencia y la criminalidad ha afectado directamente 
las políticas respecto a las policías, pues ha minimizado la urgencia en la adopción de herramientas que permitan su profesionalización (Guerrero, 2016).

Por otra parte, como se describió en la sección anterior, el subSEMun se asignaba cada año a un número limitado de municipios con base en una fórmula que consideraba, entre otros elementos, la incidencia delictiva del año anterior. Una consecuencia negativa de esta forma de otorgar el subsidio y no asegurar la ayuda a los municipios durante todos los años fue que los municipios compitieran entre sí para obtener la ayuda. Esto pudo incentivar el maquillaje de cifras de incidencia delictiva porque los municipios necesitaban mostrar que las tasas de delitos habían disminuido y cumplir así con los objetivos del subsidio, pero no podían arriesgarse a reportar una baja drástica en los índices porque ponían en riesgo la continuidad del subsidio (Sosa Altamira, 2014). Si un municipio beneficiado el año anterior reportaba una incidencia delictiva demasiado baja, ya no era elegible para el subsidio y la ayuda pasaba al siguiente municipio de la lista.

\section{No adopción de las herramientas de profesionalización y evitación de los costos}

Algunos políticos postergan la urgencia de profesionalizar a las policías municipales al afirmar que es normal que en las ciudades haya violencia y homicidios (Salmerón, 2016), o sugiriendo que no existe evidencia de que la policía municipal esté infiltrada por el crimen (Harrison, 20I6). De esta manera, los políticos evitan que el tema ingrese en la agenda pública y aplazan acciones que serían económica y políticamente costosas (Kingdon, 1995; Casar y Maldonado, 2010).

$\mathrm{Al}$ aceptar el subsidio, los municipios se comprometieron a poner en marcha el Servicio Profesional de Carrera Policial y realizar la renivelación salarial de acuerdo con el tabulador del Servicio. Sin embargo, en una gran parte de los municipios estas acciones se postergaron debido a los altos costos que implicaban o la posibilidad de que los elementos incorporados al servicio de carrera fueran despedidos:

Son insuficientes los avances que se registran en la implantación de ese servicio [de carrera ... porque] influye la preocupación de algunas administraciones municipales por las implicaciones financieras que esa estrategia significaría y, asimismo, las dificultades para implantar el Servicio Profesional de Carrera Policial en un contexto de sustitución de una parte del personal en cada ejercicio y la existencia de una proporción importante de los elementos, que no han sido evaluados en las pruebas de control de confianza o que no han aprobado estos exámenes, o bien, que 
se consideran no aptos en las evaluaciones de las pruebas de las técnicas policiales (ASF 2009, t. V, vol. II).

Hasta 20I6, los municipios que no habían puesto en práctica las herramientas de profesionalización eran aquellos que dependían en gran medida de las transferencias federales. Al comparar el avance de los municipios por su grado de capacidad financiera (GCF) ${ }^{10}$ observamos que prácticamente todos los municipios con un GCF muy alto implantaron el servicio profesional de carrera policial y la renivelación salarial, mientras que solamente $60 \%$ de los municipios con GCF muy bajo sí lo hicieron (véase cuadro 6). Esto pone de relieve la importancia de garantizar los recursos futuros de las políticas presentes.

\section{Cuadro 6.}

Municipios que implantaron el servicio profesional de carrera y la renivelación salarial

\begin{tabular}{|c|c|c|c|}
\hline & \multicolumn{3}{|c|}{ Servicio profesional de carrera y renivelación salarial } \\
\hline $\begin{array}{l}\text { Grado de capacidad financiera } \\
(\mathrm{GCF}) 2013^{11}\end{array}$ & $\% S_{i}$ & $\%$ No & $N$ \\
\hline Muy Alto & 98.8 & $\mathrm{I}+2$ & 84 \\
\hline Alto & 90.1 & $9 \cdot 9$ & III \\
\hline Medio-Alto & $84, \mathrm{I}$ & 15.9 & 44 \\
\hline Medio & 72.0 & 28.0 & 25 \\
\hline Bajo & $8 \mathrm{I} \cdot 3$ & $\mathrm{I} 8.8$ & I6 \\
\hline Muy Bajo & 60.0 & 40.0 & 5 \\
\hline Total & 89.1 & 10.9 & 285 \\
\hline
\end{tabular}

Fuente: elaboración propia con base en documentación del SESNSP, solicitudes de información pública y ASF (corte a marzo de 2016).

10 El GCF mide la suficiencia de los municipios para obtener ingresos de forma propia por medio del cobro de impuestos, y su independencia relativa respecto de las transferencias federales. ASF (2013). Índice de Desarrollo Institucional Municipal 2013 (IDIM) Nacional. http://www.asf.gob.mx/Trans/Informes/Ir2OI3i/Documentos/IDIm/2Nacional\%20IDim.pdf (consulta: 30/1I/2020).

11 No se incluyen las i6 delegaciones (hoy alcaldías) de la Ciudad de México porque no se realizó el cálculo de su GCF. 


\section{Oposición deliberada de políticos beneficiados por el sistema de patronazgo}

En un país como México, con una tradición gubernamental de uso político y discrecional de los cargos públicos, la instrumentación de un sistema policial rígido y meritocrático puede ser difícil. En otros sectores, recientemente se han suscitado oposiciones abiertas o silenciosas por parte de grupos afectados por iniciativas de reforma laboral, por ejemplo, la reforma educativa. Los sistemas laxos de reclutamiento y despido en la administración pública suelen perpetuar la poca profesionalización, el abuso de los cargos y la ineficiencia, entre otras cosas (Sundell, 2004). Este tipo de sistemas son conocidos como de "patronazgo".

Políticos y burócratas alineados al sistema de patronazgo suelen oponerse a la profesionalización de la administración pública porque la politización administrativa tiene ventajas importantes para ellos. En primer lugar, el sistema de patronazgo está abierto al clientelismo, el cual permite comprar lealtades durante los tiempos electorales, construir redes de complicidad y protección y tener "acceso discrecional a puestos públicos o a ascensos" (BID, 2OI4: IOI). En segundo lugar, el patronazgo admite que el político confiera puestos públicos a amigos, familiares, colegas, e incluso a militantes de su partido político que no consiguieron algún cargo de elección popular. En todas estas asignaciones "[n]o importan tanto las capacidades o el perfil para el cargo, sino el no quedarse sin trabajo" (Maguey, 20I2). Finalmente, la politización de la administración pública permite al patrón ganar la obediencia de los funcionarios, bajo la amenaza de despido (Merino, 2013a).

\section{Rezago de los cabildos para aprobar el reglamento de policía}

Debido a las ventajas personales y de grupo del patronazgo, políticos locales en los municipios se opusieron en un primer momento a la carrera policial y a profesionalizar sus cuerpos de seguridad. De acuerdo con la ASF, la "causa inmediata" del escaso avance que tuvo la profesionalización de las corporaciones policiacas en los primeros años fue "la falta de aprobación por parte de los cabildos del nuevo reglamento de policía [... ] homologado con el modelo nacional” (ASF, 20Io, Gasto Federalizado ramo 36). Este retraso ocasionó que no fuera sino hasta el último año del SUBSEMUN cuando la mayoría de los municipios realizaran la reestructuración de su corporación municipal en el esquema jerárquico terciario (véase cuadro 7). 


\section{Cuadro 7*}

Municipios que reestructuraron su corporación policial en el esquema jerárquico terciario

\begin{tabular}{lccc}
\hline Año & Núm. de municipios & $\%$ & \% acum. \\
\hline 2008 & 0 & 0 & 0 \\
\hline 2009 & 0 & 0 & 0 \\
\hline 2010 & 2 & 0.7 & 0.7 \\
\hline 2011 & 4 & 1.3 & 2.0 \\
\hline 2013 & IO & 3.3 & 5.3 \\
\hline 2014 & 17 & 5.6 & 11.0 \\
\hline 2015 & 35 & 11.6 & 22.6 \\
\hline No reestructuraron & 207 & 68.8 & 91.4 \\
\hline Total & 26 & 8.6 & \\
\hline
\end{tabular}

Fuente: elaboración propia con base en solicitudes de información pública al SESNSP (corte a diciembre 2015).

Este retraso impactó negativamente la renivelación salarial de los cuerpos policiales, factor fundamental para hacer atractiva la incorporación de los elementos al proceso de profesionalización (ASF, 2008, t. X, vol. I), y la promoción de una actuación de "policías de primera" (López, 20I4). Esta situación creó inconformidad entre algunos elementos de las corporaciones que consideraron injusta la asignación discrecional de los recursos reservados para la renivelación salarial. Esto quedó plasmado en diversas solicitudes de información enviadas por policías municipales en activo al SESNSP. Por ejemplo, una solicitud enviada el 5 de abril de 20 ı́ señala: ${ }^{12}$ "La mayoría de mis compañeros y yo estamos muy en desacuerdo con los manejos que hace la presidencia municipal [de los recursos del subsidio.] Además que les pedimos información y se nos es negada y nos comunican los mandos medios que ya no digamos nada porque podemos ser despedidos".

Políticos y funcionarios de alto nivel se oponen a establecer el servicio de carrera en las corporaciones locales porque la tendencia es que utilicen "las fuerzas policiacas primordialmente como un medio para proteger sus intereses políticos" (Imison, 2016). La policía municipal también es utilizada como seguridad privada de los alcaldes y miembros del cabildo (Noticias Voz e Imagen, 2016; Excélsior, 2016). En

${ }^{12}$ Folio 0002200037410 ; solicitud enviada a la entonces Secretaría de Seguridad Pública. 
otros casos, la policía municipal sirve para extraer recursos de las infracciones de tránsito sin rendir cuentas (Flores, 2016), o para que "familiares y amigos, tanto del presidente municipal como del director de seguridad pública que están inscritos en la nómina de la policía, reciban salarios de hasta 25 mil pesos quincenales" [en ese tiempo equivalía a alrededor de 2500 dólares mensuales], mientras que un policía local gana en promedio el equivalente a 350 dólares al mes (Higareda, 2017). También se han reportado casos de familiares que reciben ascensos, grados y estímulos económicos que corresponden a los policías (Hoy Estado de México, 2015). El nepotismo y los despidos injustificados son práctica normal en estas corporaciones (Ferrer, 2015; Símerman, 2016).

\section{Dificultad para identificar e instrumentar las herramientas ade- cuadas para profesionalizar}

No existe una única y mejor forma de profesionalizar la administración pública que funcione bien para todas las organizaciones, pues no todas las reformas tienen el mismo efecto en diferentes contextos (Pollitt y Bouckaert, 200I; Grindle, 20I2). La adopción de reformas que han sido exitosas en otros lugares y momentos sin la adaptación a las circunstancias particulares de una organización puede causar terribles fracasos (Sundell, 2004). Este fue un problema constante durante la profesionalización de las policías municipales.

El modelo impulsado por el subsemun se basa en el Sistema de Desarrollo Policial (Sidepol) que establece como sus objetivos centrales "garantizar el desarrollo institucional, la estabilidad laboral, la seguridad y la igualdad de oportunidades, elevar el nivel de profesionalización de las policías del país y fomentar la vocación de servicio y sentido de pertenencia" (Székely, 2012: 32). Sin embargo, las circunstancias particulares de cada municipio causaron dificultades, principalmente en la instrumentación y en la evaluación de los avances.

\section{Diseño inadecuado del plan de instrumentación de las herramientas de profesionalización}

En lenguaje de Pressman y Wildavsky (1998), en el diseño del subsemun no se consideraron algunos puntos de decisión y puntos de certificación que retrasaron la implementación de diversas herramientas del subsidio. En la cadena de eslabones de la instauración, los actores pueden jugar con los tiempos, cambiar el entorno de 
la implementación, o pedir, bajo la amenaza de bloquear cualquier avance, cambios a los fines o medios establecidos en el plan.

Como se mencionó en la sección anterior, los cabildos tardaron meses - e incluso años - para aprobar los reglamentos de policía homologados con el modelo nacional, lo que retrasó la operación de la carrera policial, de la renivelación salarial y de la reorganización jerárquica de las corporaciones. Pero este no fue el único inconveniente "no planeado" durante el proceso de implementación, sino que, además:

I. Hubo retrasos constantes en el envío de los recursos económicos desde el SESNSP a los estados, los cuales a su vez tardaron hasta un mes en transferir el dinero a los municipios (ASF, 20II, Gasto Federalizado).

2. En diversos ayuntamientos, "[e]l SESNSP no proporcionó de manera oficial a los municipios participantes en el subSEMun los lineamientos específicos, y los documentos normativos y técnicos referentes al fondo" (ASF, 20IO, Gasto Federalizado Ramo 36). Estos documentos eran necesarios para ejercer adecuadamente los recursos del subsidio. Debido a esta situación y a "la falta de asistencia del SESNSP y de la SSP, a los municipios" (ASF, 2009, t. V, vol. II), algunas preguntas técnicas sobre el manejo del subsidio fueron enviadas por funcionarios municipales como solicitudes de información pública al SESNSP.

3. El SeSnsp nunca estableció en las reglas de operación del subsemun la necesidad de que los municipios contaran con un área específica para administrar el subsidio. Por esta razón, en los ayuntamientos siempre existieron "insuficiencias en la capacidad técnica, administrativa y organizativa para realizar una eficiente gestión del fondo" (ASF, 20IO, Gasto Federalizado Ramo 36). Esta situación afectó negativamente el impacto potencial del subsidio para profesionalizar las policías locales. De hecho, la ausencia de un sistema de carrera dentro de las administraciones públicas de los ayuntamientos fue un elemento negativo para el SUBSEMUN debido a la "[i]nsuficiente institucionalización de los procesos y elevada rotación de personal en cada cambio de administración, lo que conlleva la pérdida de experiencia y capacidades" (ASF, 2009, t. V, vol. II).

\section{Evaluación inexacta de los avances de la profesionalización}

La revisión periódica que realizó el SESNSP a los municipios sobre el proceso de profesionalización estuvo siempre limitada y se centró en productos más que en 
resultados. Es decir, no existe una verdadera evaluación de desempeño que permita saber si efectivamente se están profesionalizando los policías municipales, o si están siendo entrenados en las academias específicamente para pasar las pruebas de habilidades/destrezas y de conocimientos de la función. Ambas pruebas tuvieron un porcentaje creciente de policías aprobados desde 2012 (véase gráfico 2).

\section{Gráfico 2.}

Porcentaje de policías aprobados en las evaluaciones de habilidades, destrezas y conocimientos de la función

Habilidades y destrezas Conocimientos de la función

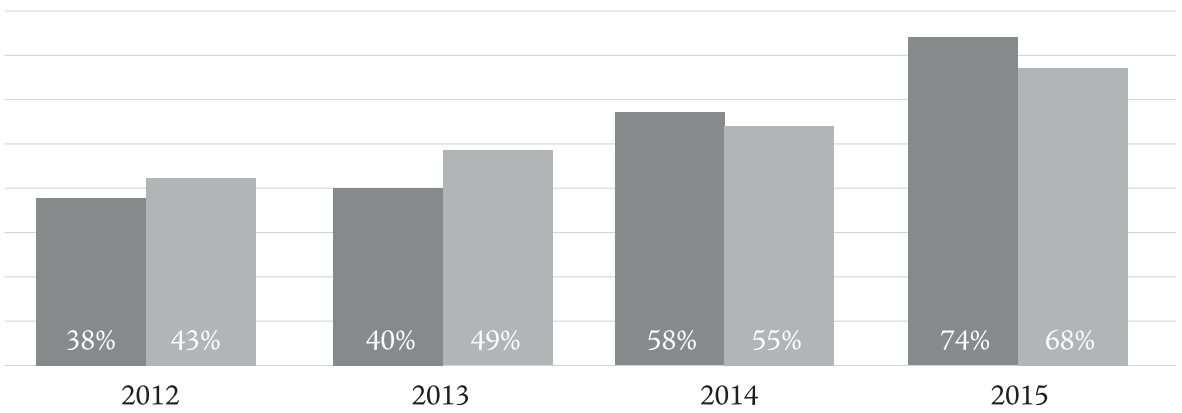

Fuente: elaboración propia con base en solicitudes de información pública al SESNSP (diciembre, 2015).

Por otra parte, el SESNSP utilizó las estadísticas de incidencia delictiva como un indicador del éxito de las políticas de profesionalización policial. Estos números no solamente son inadecuados para medir el desempeño real de los policías (Arango y Lara, 2007), sino que su aceptación y adecuado uso son complicados debido a lógicas de competencia y de pugna burocrática (González Gómez, 20Io).

El seSnsp también evaluó el avance de la profesionalización por medio del número de policías que aprobaron las evaluaciones y los controles de confianza aplicados por los CECC. Estas pruebas, sin embargo, han sido cuestionadas en su eficacia (Meyer, 20I4), y existen casos de policías aprobados en estos controles que han sido vinculados posteriormente a delitos (Animal Político, 2013; Alzaga, 2015; ZonaFranca, 2014). Una nota de 2017 pone de manifiesto esta situación: “Granados Torres detalló que entre estas bajas se encuentran los [cinco] policías que operaban una banda delictiva en el estado y que fue desmantelada el pasado i2 de abril, y 
subrayó que en el caso de los elementos policiacos del estado involucrados ninguno había reprobado el examen de control de confianza" (Munguía, 2017).

Además, los resultados de estas pruebas están sujetos al uso discrecional de los políticos y funcionarios en turno, como lo han denunciado policías y organizaciones no gubernamentales (Reza, 2013). Un ejemplo concreto se describe en el informe de 20 I de la ASF: "los resultados de las evaluaciones que realizó el Centro de Evaluación de Control de Confianza de la Paz, Baja California Sur, las resguarda el presidente municipal y no las transmite a las áreas correspondientes, para determinar las acciones de control" (ASF, 20II, Gasto Federalizado).

Debido a esta evaluación inexacta de los avances, no existe certeza sobre el grado real de profesionalización de las policías municipales. Por ejemplo, no hay claridad sobre qué tanto impacta el nivel educativo de los policías en la profesionalización, ya que únicamente $4 \mathrm{I} .3 \%$ de los policías locales tienen preparatoria o estudios superiores (INEGI, 20I5).

\section{Condiciones culturales y organizacionales anteriores a la reforma}

La profesionalización del sector público no debe incluir solamente reformas a la ley, sino también a las costumbres, las rutinas y la cultura de las organizaciones (Arellano, 2010). Esto es algo esencial en las corporaciones policiales en las cuales tradicionalmente ha prevalecido una cultura voluble de la legalidad (Tello, 2013; Meyer, 20I4). Sin embargo, en el subsemun hubo dos obstáculos en este sentido: desatención a la cultura policial y una tendencia a sustituir esa cultura por la militar.

\section{Resistencia a cambiar la cultura policial}

De acuerdo con el diagnóstico sobre los factores causales de la problemática de la seguridad pública,"[1] os bajos salarios policiales no son la única fuente de la corrupción, pues también incide la ausencia de práctica y cultura profesional" (ASF, 2013b). Para solventar este punto, el Programa Nacional de Seguridad Pública 2008-2012 incluyó como uno de sus objetivos "[f] ortalecer la cultura de la legalidad [...] así como el respeto y protección a los derechos humanos de la población por parte de los encargados de la seguridad pública en los tres órdenes de gobierno" (Programa Nacional de Seguridad Pública 2008-2012).

A pesar de esto, una de las observaciones constantes de la ASF sobre los resultados del SUBSEMUN fue la poca atención del SESNSP para modificar la cultura organizacional dentro de las corporaciones municipales. La ASF recomendó en 2008 
dedicar recursos para "[d]esarrollar una nueva cultura del servicio policial, para que sus integrantes estén orgullosos de pertenecer a las corporaciones policiales y que la sociedad los reconozca" (ASF, 2008, t. X, vol. I). En años posteriores la ASF continuó comentando el débil desarrollo en varios municipios de una nueva cultura policial (ASF, 20IO, Gasto Federalizado Ramo 36; ASF, 20II, Gasto Federalizado subSEMUN). Hasta la desaparición del subsidio en 2015, nunca se incluyó alguna iniciativa para evaluar el cambio de cultura dentro de las corporaciones.

Por otra parte, además de la ausencia de una cultura policial adecuada, la ASF también detectó culturas organizacionales incongruentes con la evaluación de resultados y la difusión de mejores prácticas. Por ejemplo, en 2010 una observación general fue que en muchos municipios y sus corporaciones policiales "[n]o existe una cultura definida para la prevención y evaluación de los resultados", lo que en la práctica, reduce el efecto de la retroalimentación que pudiera darse para mejorar la administración y el impacto del subsemun (ASF, 20IO, Gasto Federalizado Ramo 36).

El riesgo de no impulsar una nueva cultura dentro de las corporaciones municipales y los ayuntamientos es que se mantienen rutinas y costumbres que pueden afectar negativamente los esfuerzos legales y normativos para modificar el comportamiento de los elementos y profesionalizarlos. En última instancia, se espera que el cambio en la norma afecte paulatinamente las acciones y costumbres dentro de la organización, al grado en que sus miembros la hagan propia. Sin embargo, este no es un proceso automático (Cejudo, 2007). Por ejemplo, la adopción de nuevas tecnologías y herramientas de trabajo no transforma automáticamente las organizaciones, sino que estas tecnologías y herramientas se acomodan dentro de las costumbres de los receptores, los cuales siempre mantienen independencia para definir aquellos aspectos a rescatar (Hill et al., 1998).

Para ayudar a modificar los patrones culturales y organizaciones dentro de las corporaciones municipales, la ASF recomendó la posibilidad de becar a algunos elementos municipales para tomar cursos de capacitación en el extranjero. Esto no solo con el objetivo de "aumentar los conocimientos en materia de prevención y seguridad pública", sino además para poder "observar otras culturas" y transmitir estas experiencias a los demás elementos de las corporaciones (ASF, 2008, t. X, vol. I). Las visitas a otros países han mostrado tener una relación positiva con la comunicación interpersonal, respuestas adecuadas en situaciones ambiguas y la apertura a intentar soluciones distintas a las ya conocidas (Swenson y Casmir, 1998; Gertler, 1995). Sin embargo, dentro del subSEMUN no se incluyó en ningún año presupuesto 
ni objetivos relacionados con visitas, cursos o experiencias de trabajo de los policías municipales en el extranjero.

\section{Intento por integrar la cultura militar}

Ante la falta de atención al cambio de la cultura policial, algunas corporaciones policiales mexicanas han integrado en sus filas a militares. Por ejemplo, el municipio de Tijuana, Baja California, dio facilidades a cadetes del ejército para revalidar materias en la Academia Estatal de Policía (AEP). Esta iniciativa tuvo el objetivo de atraer elementos frente a la falta de policías en el ayuntamiento (Martínez, 2014). De acuerdo con el titular de la Secretaría de Seguridad Pública municipal, el reacondicionamiento cultural sería algo innecesario, pues los cadetes "ya traen una capacitación, ya nada más sería reforzar los conocimientos en cuanto al área y el municipio al que serían destinados los elementos para acortar tiempos" (Martínez, 2014).

Con este tipo de iniciativas se abandonan los valores esenciales del trabajo policiaco (proteger a la población civil) y se adoptan los de la profesión militar (defensa ante agresiones externas) (Moloeznik y Suárez, 2013).

La experiencia en años recientes ha mostrado que si no se contrarresta la cultura militar con una policial, el uso de la fuerza se convierte en la primera y mejor respuesta frente al crimen, y se descuida el trabajo de prevención del delito (Meyer, 20I4; Moloeznik y Suárez, 2013). Además, en estos casos el esfuerzo de profesionalización de las fuerzas policiales pasa a un segundo plano (Withers et al., 2010).

\section{Esfuerzos para deconstruir y reconstruir la reforma}

Cualquier reforma del sector público "es seguida habitualmente por esfuerzos para deconstruir y reconstruir lo que se ha creado" (Grindle, 20I2: II). Estos esfuerzos usualmente responden a intereses económicos o políticos. Por ejemplo, una crisis fiscal o de legitimidad del régimen puede precipitar iniciativas para modificar el rumbo o la intensidad de la reforma (Nieto et al., 2014). En el caso de las policías en México, la urgencia de su profesionalización surgió ante "la necesidad de poner coto a una dinámica delictiva creciente que estaba minando el Estado de derecho" (ASF, 2008, t. IX, vol. 2). Frente a coyunturas futuras, el SESNSP probablemente se vea forzado a modificar, repensar o incluso abandonar el nuevo modelo policial para adaptarse a las nuevas circunstancias que enfrentan las fuerzas del orden público. 


\section{Primacía de objetivos políticos en las propuestas para transformar la reforma de profesionalización}

Frente a presiones políticas y a la desaceleración económica del país, el SUBSEMUN y el SPA fueron sustituidos por el FORTASEG. Este nuevo subsidio combina algunos objetivos de ambos subsidios con un ahorro para la federación de i 700 millones de pesos (alrededor de 85 millones de dólares) (SESNSP, 2016). Este subsidio termina con los objetivos promovidos por el subsemun y prioriza el desarrollo de capacidades para aplicar el Nuevo Sistema de Justicia Penal (sesnsp, 20I6). Este cambio parece responder más a un clima de "interpretación, debate y lucha" de la política (Mahoney y Thelen, 20I0) que a un cambio real en la estrategia de seguridad.

Por otra parte, la desaparición de 43 estudiantes en Ayotzinapa, Guerrero, en 2014 reavivó en la esfera pública la propuesta de disolver las policías locales e integrarlas en 32 corporaciones estatales que cumplirían sus funciones policiacas como un "mando único" en cada estado. Esta iniciativa no es nueva, sino que fue anunciada originalmente en octubre de 2010 por el entonces presidente Felipe Calderón. La propuesta de reforma de ley fue enviada a la Cámara de Senadores pero no fue aprobada (Gamboa, 2010).

En años posteriores surgieron diferentes iniciativas relativas al "mando único", cada una con planteamientos específicos para fortalecer o sustituir las policías de los ayuntamientos (Bautista, 2016). La propuesta del Ejecutivo federal planteó que las policías locales fueran sustituidas por un mando único porque "las policías municipales no han sido una opción institucional viable para atender las necesidades de seguridad en gran parte del país" (Peña Nieto, 20I4). Otra propuesta no buscó la sustitución de las policías municipales por policías estatales porque "[1]as policías estatales no son necesariamente mejores que las policías municipales" ya que "[1] as capacidades de prevención y persecución del delito de la mayoría de las policías estatales son bastante limitadas, en algunos casos nulas" (Barbosa, 20I6). Una tercera propuesta buscó mantener la forma en que se organizan las policías porque una reestructura no puede corregir su desempeño. Para mejorar las policías, afirmaba esta propuesta, es necesario antes resolver cuestiones más elementales como la "cultura de la impunidad e incentivos para dedicarse al crimen" (Bartlett, 2016). Por esta razón, la iniciativa se centraba en la provisión de mayores recursos económicos a los municipios y el fortalecimiento del Estado de derecho y las instituciones de justicia.

Cada una de estas propuestas buscaba deconstruir y reconstruir la política de profesionalización policial, lo que incrementaba el riesgo de politizar la discusión y olvidar el objetivo de toda reforma al servicio civil: "mejorar el rendimiento de 
las organizaciones del sector público y, por lo tanto, los servicios que reciben los ciudadanos" (Velarde et al., 20I4: 3).

\section{Buenas prácticas para superar los obstáculos prácticos, políti- cos y administrativos}

Los obstáculos que enfrentó el SUBSEMUN descritos en la sección anterior no son inamovibles ni insuperables. Esta sección presenta algunas recomendaciones y buenas prácticas ofrecidas en la literatura de políticas públicas para superar las dificultades en la aceptación e implantación de políticas en contextos de baja institucionalización como México. El cuadro 8 presenta un resumen de estas buenas prácticas y a continuación se describe cada una de ellas.

\section{Cuadro 8.}

Buenas prácticas para superar los obstáculos a la profesionalización de las policías locales

\begin{tabular}{|c|c|}
\hline Obstáculo & Buenas prácticas \\
\hline Predilección por el statu quo & $\begin{array}{l}\text { Elaborar diagnósticos independientes sobre la situa- } \\
\text { ción de la policía } \\
\text { Realizar campañas para vincular ciertas prácticas } \\
\text { con ideas particulares (por ejemplo, nepotismo con } \\
\text { corrupción y conflicto de interés) }\end{array}$ \\
\hline $\begin{array}{l}\text { Oposición deliberada de } \\
\text { políticos beneficiados por el } \\
\text { sistema de patronazgo }\end{array}$ & $\begin{array}{l}\text { - Aumentar la presión social para modificar los incen- } \\
\text { tivos de los políticos } \\
\text { + Formar coaliciones con think tanks, onGs, etc. } \\
\text { + Aprovechar momentos coyunturales para promover } \\
\text { la reforma policial }\end{array}$ \\
\hline $\begin{array}{l}\text { Dificultad para identificar e } \\
\text { instrumentar las herramien- } \\
\text { tas adecuadas para profesio- } \\
\text { nalizar }\end{array}$ & $\begin{array}{l}\text { - Tener claridad sobre los objetivos que se quieren } \\
\text { lograr con la reforma } \\
\text { Analizar, con tanta objetividad como sea posible, las } \\
\text { ventajas y desventajas de los modelos de profesiona- } \\
\text { lización (por medio de estudios comparativos) } \\
\text { + Planear adecuadamente la instrumentación: tener dis- } \\
\text { posición para adaptar el plan; considerar cada punto } \\
\text { de decisión y certificación; contar con un mapa de } \\
\text { todos los participantes involucrados en el proceso } \\
\text { Dotar a los implementadores de suficientes atribu- } \\
\text { ciones, capacidades y herramientas }\end{array}$ \\
\hline
\end{tabular}




\begin{tabular}{|c|c|}
\hline Obstáculo & Buenas prácticas \\
\hline $\begin{array}{l}\text { Condiciones culturales y } \\
\text { organizacionales anteriores } \\
\text { a la reforma }\end{array}$ & $\begin{array}{l}\text { - Entender las culturas, contextos e instituciones que } \\
\text { se están intentando reformar } \\
\text { + Adaptar las herramientas de profesionalización a las } \\
\text { culturas organizacionales particulares }\end{array}$ \\
\hline $\begin{array}{l}\text { Esfuerzos para deconstruir y } \\
\text { reconstruir la reforma }\end{array}$ & $\begin{array}{l}\text { - Formar coaliciones con ONG para monitorear y } \\
\text { denunciar intenciones de regresar a modelos patri- } \\
\text { monialistas } \\
\text { + Mantener presión de los votantes hacia los grupos } \\
\text { políticos }\end{array}$ \\
\hline
\end{tabular}

Fuente: elaboración propia

En primer lugar, es conveniente identificar y publicitar qué es lo que no funciona adecuadamente, qué es necesario reformar y cómo se medirá el progreso (IEG, 2008). En 2016 el Observatorio Nacional Ciudadano, una organización no gubernamental mexicana, solicitó al secretario de Gobernación que, a diferencia de lo que ha sucedido, "las políticas públicas que cuentan con apoyo federal estén sustentadas en diagnósticos, que cuenten con indicadores de impacto y que eventualmente se evalúe si han producido resultados" (Rivas, 2016).

Estos diagnósticos y soluciones deben enmarcarse dentro de una argumentación de problema público (Subirats, Knoepfel, Larrue y Varonne, 2008; Merino, 20II). Si las deficiencias de las corporaciones policiales se logran colocar en la agenda pública, será más difícil que los tomadores de decisiones ignoren estos problemas. También pueden realizarse campañas publicitarias sobre ciertos fenómenos, por ejemplo, vincular el término nepotismo con la corrupción y el conflicto de intereses (Chittock, 2015).

En segundo lugar, es esencial cambiar los incentivos de los tomadores de decisiones (McGrath, 20I3). Es conveniente unir fuerzas con think tanks, organizaciones no gubernamentales, centros de investigación y organismos internacionales para crear mayor presión social y aumentar los costos políticos de mantener sin cambios las corporaciones policiales (BID, 20I4).

Para alcanzar ese objetivo se pueden aprovechar momentos coyunturales para promover una reforma. Las ventanas de oportunidad son momentos cruciales que pueden ser aprovechados por los actores para impulsar problemas o políticas preferidas (Kingdon, 1995). El tema de una reforma policial puede colocarse con mayor facilidad en la agenda pública durante una crisis de confianza, o se puede agregar la reforma a "otros objetivos políticos importantes y urgentes, como mejorar la 
ejecución del gasto público o superar crisis políticas apremiantes" (BID, 20I4ः 88). La evidencia empírica muestra que para avanzar en un proceso de reforma administrativa se necesita siempre una acción oportuna en un momento políticamente importante (Grindle, 2012).

En tercer lugar, es necesario analizar, con tanta objetividad como sea posible las ventajas y desventajas de los distintos modelos de reforma disponibles para profesionalizar - o seguir profesionalizando- las corporaciones policiales. Esto es difícil porque no pueden aplicarse soluciones prefabricadas que hayan funcionado correctamente en otros lugares. Por otra parte, es difícil tener certeza sobre el éxito relativo de una reforma administrativa porque

es difícil recolectar evidencia de lo que funcionó y lo que no, y por qué. Los partidarios de una reforma en particular le atribuyen todo lo bueno que le pasó y, del mismo modo, los críticos le atribuyen a la misma reforma casi cualquier cosa mala que haya sucedido, pero ambas partes tienen dificultad para probar estas atribuciones (Pollitt y Bouckaert, 2014: 214).

Al elegir un modelo de profesionalización de las policías se debe aceptar que ninguna herramienta es perfecta ni resolverá todos los problemas en el actuar policial. Sin embargo, se pueden establecer procedimientos para modificar gradualmente lo que no funciona y así adecuar poco a poco la reforma para que sea exitosa. Siempre es posible aprovechar el proceso de implementación "como escenario para el aprendizaje, la mejora continua y el desarrollo de capacidades" (BID, 20I4: 137).

En cuarto lugar, se pueden aplicar algunas lecciones ofrecidas por Pollitt y Bouckaert (20I4) para hacer una mejor elección de modelos de reforma administrativa: tener claridad sobre los objetivos que se quieren lograr con la profesionalización administrativa, ya que una reforma implica necesariamente un trade-off entre diferentes valores subyacentes (eficacia o eficiencia, profesionalización o diversidad, etc.),y utilizar una comparación internacional que puede tener mayor fuerza iluminadora e informativa, la cual tiene menos sesgos que un estudio centrado en un solo país porque no depende necesariamente de los números "maquillados" de los políticos nacionales.

En quinto lugar, para enfrentar a jugadores que pudieran obstruir la implementación, Pressman y Wildavsky presentan tres recomendaciones puntuales: a) disposición para modificar el plan para adaptarlo según sea necesario: “[u]na razón esencial de la supervivencia de los programas es que se adaptan a su medio durante lapsos prolongados" (1998ः 207); b) una buena planeación, es decir, considerar cada 
uno de los puntos de decisión y de certificación que sucederán a lo largo de la implementación, y c) tener un mapa completo de los participantes involucrados en el proceso $-\mathrm{y}$ se debe incluir a los jugadores con veto en el poder Legislativo(Tsebelis, 1995).

En sexto lugar, es importante entender las culturas y los contextos particulares de las corporaciones policiales que se están intentando reformar. Si este análisis no se incluye en las consideraciones iniciales, es probable que cualquier tentativa de profesionalización no tenga éxito (Cejudo, 2007). Después de todo,

[1] a viabilidad organizacional de la acción política es una variable crítica, pero no es una variable exclusivamente técnica: no se puede resolver simplemente a partir de un análisis de factibilidad de recursos, sino que requiere comprender la lógica organizativa, la cultura de acción e interpretación, y la red de relaciones y significados que mueven a las personas que la componen (Arellano, 2010: 64).

Las diferentes herramientas de profesionalización policial deben adaptarse a las culturas organizacionales particulares, aunque esto signifique diversas carreras policiales o variaciones de un modelo único que considere diferentes valores, objetivos, reglamentos, prácticas y niveles de efectividad (ASF, 2013).

Finalmente, para ayudar a que un proceso de profesionalización se mantenga vivo y eficaz se pueden formar coaliciones con onGs y otros actores relevantes para monitorear los avances de implementación, y denunciar las intenciones de regresar a un uso político de las policías. Los grupos políticos presionados por los votantes pueden prevenir intentos de retornar a policías que solo responden a incentivos políticos. El apoyo de la sociedad a la reforma es fundamental para su mantenimiento a través del tiempo (Meyer, 20II).

\section{Conclusión}

El subSEMUn cumplió únicamente de forma limitada el objetivo de profesionalizar las policías locales de los municipios prioritarios de México debido a obstáculos prácticos, políticos y administrativos descritos en este texto: una marcada predilección por el statu quo; una oposición deliberada por parte de políticos y policías beneficiados por el sistema de patronazgo; dificultad para identificar e instrumentar las herramientas adecuadas para la profesionalización policial; condiciones culturales y organizacionales inadecuadas para realizar los cambios necesarios, y una 
tendencia constante a repensar y reconstruir la reforma sin haber concluido con los planes iniciales.

Estos obstáculos, sin embargo, no son insuperables y pueden llevarse a cabo estrategias y vínculos con actores varios para avanzar en cambios positivos en materia de seguridad. Algunas buenas prácticas y recomendaciones de la literatura se presentaron en el apartado anterior. Considerar estos puntos en el diseño y la operación de futuros programas de fortalecimiento institucional de las policías locales puede ayudar a conseguir mejores resultados y un impacto positivo.

Un punto que debe considerarse es que la paciencia de la ciudadanía y de los políticos es un valor esencial en todo el proceso. Debe existir conciencia de que una vez elegido un modelo concreto de profesionalización es necesario mantenerlo sin cambios intempestivos (Pollitt y Bouckaert, 20I4). Por desgracia, el subsemun fue sustituido en 2016 por un programa diferente de profesionalización de las policías locales sin haber aprendido suficiente de los aciertos y desaciertos. Con la llegada del gobierno de Andrés Manuel López Obrador se replanteó una vez más el modelo de seguridad para las policías locales, ${ }^{13}$ sin tomar en cuenta los resultados positivos y negativos de programas pasados, dejando hasta el día de hoy cabos sueltos en las corporaciones policiales locales.

\section{Referencias}

$90^{\circ}$ grados

2020 "Autoridades y criminales delinquen juntos en Tacámbaro, denuncian habitantes; Tras ejecución de civil por policías y sicarios, silencio del Gobierno estatal", 02/04/2020. http://www.noventagrados.com.mx/ seguridad/autoridades-y-criminales-delinquen-juntos-en-tacambaro-denuncian-habitantes-tras-ejecucion-de-civil-por-policias-y-sicarios-silencio-del-gobierno-estatal.htm [consulta: 30/II/2020].

Aguilar Villanueva, Luis

1992 El estudio de las políticas públicas, México, Miguel Ángel Porrua. Alzaga, Ignacio

2015 "El 75\% de policías de Iguala aprobó control de confianza... local". Milenio, 8 de octubre, http://www.milenio.com/politica/75-_de_poli-

${ }^{13}$ http://www.asf.gob.mx/Trans/Informes/IR2OI3i/Documentos/IDIm/2Nacional\%2O IDIM.pdf 
cias_aprobo_control_de_confianza-Felipe_Flores_Velazquez-normalistas_O_386961336.html [consulta: 30/II/2020].

Animal Político

2013 "Policías vinculados a caso Heaven habían aprobado control de confianza," 24 de septiembre. http://www.animalpolitico.com/2013/o9/ policias-vinculados-a-caso-heaven-estaban-certificados/ [consulta: 30/II/2020].

Arango Durán, Arturo y Cristina Lara Medina

2007 "Las estadísticas de seguridad pública en México. Situación y perspectivas" en Luis González Placencia, José Luis Arce Aguilar y Metztli Álvarez, Aproximaciones empiricas al estudio de la inseguridad, México, Porrúa.

Auditoría Superior de la Federación 2008 Auditorías al gasto ejercido en subsemun. http://www.asf.gob.mx/ Default/Index [consulta: 30/II/2020].

Auditoría Superior de la Federación 2009 Auditorías al gasto ejercido en subsemun. http://www.asf.gob.mx/ Default/Index [consulta: 30/II/2020].

Auditoría Superior de la Federación 20 Io Auditorías al gasto ejercido en subsemun. http://www.asf.gob.mx/ Default/Index [consulta: 30/II/2020].

Auditoría Superior de la Federación 20Ir Auditorías al gasto ejercido en subsemun. http://www.asf.gob.mx/ Default/Index [consulta: 30/II/2020].

Auditoría Superior de la Federación 2012 Auditorías al gasto ejercido en subSemun. http://www.asf.gob.mx/ Default/Index [consulta: 30/II/2020].

Auditoría Superior de la Federación 2013 Auditorías al gasto ejercido en subsemun. http://www.asf.gob.mx/ Default/Index [consulta: 30/II/2020].

Auditoría Superior de la Federación

2013a Evaluación número 230 "Servicios de carrera en el Estado federal". http://www.asf.gob.mx/Trans/Informes/Ir2OI2i/Documentos/Auditorias/2012_0230_a.pdf [consultaः 30/1I/2020].

Auditoría Superior de la Federación

2013b Evaluación número 1207"Política Pública de Seguridad Pública”, http:// www.asf.gob.mx/Trans/Informes/Ir2or3i/Documentos/Auditorias/2013_I207_a.pdf [consulta: 30/II/2020]. 
Auditoría Superior de la Federación

2014 Auditorías al gasto ejercido en subsemun. http://www.asf.gob.mx/ Default/Index [consulta: 30/II/2020].

Auditoría Superior de la Federación

2015 Auditorías al gasto ejercido en subsemun. http://www.asf.gob.mx/ Default/Index [consulta: 30/II/2020].

Barbosa Huerta, Miguel 2016 "Iniciativa con Proyecto de Decreto", 2 febrero, LXIII/ISPO-75/60404.

Bartlett Díaz, Manuel 2016 "Iniciativa con Proyecto de Decreto", 4 febrero, LXIII/ISpo-77/60503. Bautista, Omar

2016 "Claves para entender la propuesta de Mando Único", La Razón, io de marzo, http://www.razon.com.mx/spip.php?article299653 [consulta: $30 / \mathrm{II} / 2020]$.

Cámara de Diputados

20II Memoria de la mesa redonda: mando único policial, México, Centro de Estudios de Derecho e Investigaciones Parlamentarias.

Campos Garza, Luciano

2017 "Cae policía de Monterrey por robo de auto con violencia", Proceso, 20/o7, http://www.proceso.com.mx/495609/cae-policia-monterrey-robo-auto-violencia [consulta: 30/II/2020].

Carbonell, Miguel

2004 Constitución Política de Los Estados Unidos Mexicanos, Comentada y concordada, México, Universidad Nacional Autónoma de México.

Carreño Carlón, José y Saúl López Noriega

2015 “Por qué un manual de periodismo judicial?”, Nexos, julio 2, http:// eljuegodelacorte.nexos.com. $\mathrm{mx} / ? \mathrm{p}=4767$ [consulta: $30 / \mathrm{II} / 2020$ ].

Casar, María Amparo y Claudia Maldonado

2010 "Formación de agenda y procesos de toma de decisiones: una aproximación desde la ciencia política”, en Problemas, decisiones y soluciones: enfoques de políticas públicas, México, Fondo de Cultura Económica.

Cejudo, Guillermo

2007 New Wine in Old Bottles: How New Democracies Deal with Inherited Bureaucratic Apparatuses. The Experiences of Mexico and Spain, Documento de trabajo \#19o, Centro de Investigación y Docencia Económicas (CIDE). 


\section{Chittock, Matt}

2015 "Where a job is never regarded as $100 \%$ yours", ввс.com, 7 de octubre, http://www.bbc.com/capital/story/20151006-where-a-job-is-neverregarded-as-IOO-yours [consulta: 30/II/2020].

Cortez, Edgar

2016 "La realidad aislada del gobierno mexicano", Animal Político, 20 de junio. http://www.animalpolitico.com/blogueros-blog-invitado/2016/o6/20/la-realidad-aislada-del-gobierno-mexicano/ [consulta: $30 / \mathrm{II} / 2020]$.

Davis, Diane E.

2006 "Undermining the Rule of Law: Democratization and the Dark Side of Police Reform in Mexico", Latin American Politics and Society, 48(I), pp. 55-86. https://doi.org/10.1III/j.1548-2456.2006.tboo338.x

Delgado Castañeda, Ranulfo

2012 "Inexplicable subejercicio en seguridad pública", Revista de los Centros de Estudios de la Cámara de Diputados, 2(I7), septiembre, pp. 28-35.

Diario Oficial de la Federación (DOF)

20II Reglas para el otorgamiento del subsidio a los municipios y, en su caso, a los estados cuando tengan a su cargo la función o la ejerzan coordinadamente con los municipios, así como al Gobierno del Distrito Federal en sus demarcaciones territoriales. 28 de enero, http://dof.gob.mx/nota_detalle. php? codigo $=5175985 \&$ fecha $=28 /$ oI $/ 2$ II [ consulta: $30 / \mathrm{II} / 2020$ ].

El Heraldo de México

2020 "video: Policías de San Luis son captados robando un auto en complicidad con ladrón", I2/II/2020, https://heraldodemexico.com.mx/nacio$\mathrm{nal} / 2020 / \mathrm{II} / \mathrm{I} 2 /$ video-policias-de-san-luis-son-captados-robando-unauto-en-complicidad-con-ladron-224816.html [consulta:30/II/2020].

Excélsior

2016 "Exhiben a mando policial usando patrulla para ir al súper", 29/03/2016, http://www.excelsior.com.mx/nacional/2016/03/29/1083503 [consulta: $30 / \mathrm{II} / 2020]$.

Ferrer, Sergio

2015 "Despidos injustificados, nepotismo y maltrato a policías municipales de Tlapa", i3 de febrero, Los Angeles Press, http://www.losangelespress. org/despidos-injustificados-nepotismo-y-maltrato-a-policias-municipales-de-tlapa/ [consulta: 30/1I/2020]. 
Flores Noriega, Iván

2016 "Exigen cuota de 5 infracciones diarias a policías viales de Santa Lucía", 9 de abril, Noticias Voze Imagen, http:/ /www.nvinoticias.com/nota/5162/ exigen-cuota-de-5-infracciones-diarias-policias-viales-de-santa-lucia [consulta: 30/II/2020].

Gamboa Montejano, Claudia

2010 Análisis de la Iniciativa de Mando Único Policial presentada por el Ejecutivo Federal ante el Senado de la Republica, Centro de Documentación, Información y Análisis, http://www.diputados.gob.mx/sedia/sia/spi/ SPI-ISS-30-IO.pdf [consulta: 30/II/2020].

Gertler, Meric

1995 'Being There': Proximity, Organization, and Culture in the Development and Adoption of Advanced Manufacturing Technologies", Economic Geography, 7I(I), pp. I-26. https://doi.org/I0.2307/I44433

González Gómez, Javier

2010 "La evaluación de la actividad gubernamental: premisas básicas y algunas anotaciones sobre la experiencia mexicana”, en Méndez, J. (coord.), Los grandes temas de México. XIII. Políticas Públicas, México, El Colegio de México.

Grindle, Merilee

2012 Jobs for the Boys. Harvard: Harvard University Press, https://doi. org/10.4159/harvard.9780674065185

Guerrero Gutiérrez, Eduardo

2016 "La inseguridad 2013-2015", Nexos, I de enero, http://www.nexos.com. $\mathrm{mx} / ? \mathrm{p}=27269$ [consulta: $30 / \mathrm{II} / 2020]$.

Harrison, Aurora

2016 "No hay elementos para afirmar que la policía de Acapulco está infiltrada por el crimen: Astudillo", El Sur, 23 de mayo, http://suracapulco. $\mathrm{mx} / \mathrm{I} /$ no-hay-elementos-para-afirmar-que-la-policia-de-acapulco-esta-infiltrada-por-el-crimen-astudillo/ [consulta: 2I/o8/2016].

Higareda, Diana

2017 "Policía municipal, reprobada y con bajos salarios", El Universal, 09/07/2017. http://www.eluniversal.com.mx/articulo/periodismo-de-datos/2017/o7/9/policia-municipal-reprobada-y-con-bajos-salarios [consulta: OI/04/2020]. 
Hill, Carole; Karen Loch, Detmar Straub y Kamal El-Sheshai

1998 "A Qualitative Assessment of Arab Culture and Information Technology Transfer", Journal of Global Information Management, 6(3), pp. 29-38, https://doi.org/10.4018/jgim.1998070103

Hoy Estado de México

2015 'Exigen 'polis' renuncia de su director en Ixtlahuaca, 23 noviembre, http://www.hoyestado.com/2015/II/exigen-polis-renuncia-de-su-director-en-ixtlahuaca/ [consulta: 30/II/2020].

Independient Evaluation Group (IEG)

2008 Public Sector Reform: What Works and Why? An IEG Evaluation of World Bank Support, Washington, World Bank, https://openknowledge.worldbank.org/bitstream/handle/I0986/6484/448180PUBoBox310onlyio9780821375891.pdf? sequence $=\mathrm{I} \&$ is Allowed $=y[$ consulta: $30 / \mathrm{II} / 2020$ ].

Imagen del Golfo

2017 “Cae policía de Las Choapas con auto robado", 17/o7, http://imagendelgolfo.mx/noticiasveracruz/policiaca/4II97777/cae-policia-de-laschoapas-con-auto-robado.html [consulta: 30/II/2020].

Imison, Paul

2016 "Los esfuerzos de México por combatir la corrupción en la policía siguen fallando", Vice News, 28 de marzo, https://news.vice.com/es/ article/los-esfuerzos-de-mexico-por-combatir-corrupcion-en-polica-siguen-fallando [consulta: 30/II/2020].

Instituto Nacional de Estadística y Geografía (INEGI)

2015 Censo Nacional de Gobiernos Municipales y Delegacionales 2015.

Justice in Mexico Project

2011 Justiciabarómetro. Diagnóstico Integral de la Policía Municipal de Ciudad Juárez, Trans-Border Institute.

Kingdon, John

1995 Agendas, alternatives and public policies, Nueva York, Harper.

La Prensa de Monclova

2017 "Cae por ejecuciones policía monclovense", 24/o6, http://laprensademonclova.com/portal/2017/06/24/cae-por-ejecuciones-policia-monclovense/ [consulta: 30/II/2020].

López Pastén, Guillermo

2014 "Policía Municipal, de los eslabones más débiles en la procuración de justicia", Milenio, 27 de noviembre, http://www.milenio.com/policia/ 
municipal-eslabones-debiles-procuracion-justicia_o_416958522.html [consulta: $30 / \mathrm{II} / 2020$ ].

Maguey, Hugo

2012 "Aquí nadie se queda sin hueso", Animal Político, i4 de febrero, http:// www.animalpolitico.com/2012/o2/aqui-nadie-se-queda-sin-hueso/ [consultaः 30/II/2020].

Mahoney, James

2008 "Toward a Unified Theory of Causality", Comparative Political Studies, 4I(4/5), pp. 412-436. https://doi.org/I0.1177/ooro414007313115

Mahoney, James y Kathleen Thelen

2010 "A Theory of Gradual Institutional Change" en Mahoney, James y Thelen, Kathleen (eds.), Explaining Institutional Change, Nueva York, Cambridge University Press, https://doi.org/IO.IOI7/Сво9780511806414

Martínez, Gabriela

2014 "Del servicio militar a la Policía Municipal en menos tiempo", Milenio, I de abril, http://www.milenio.com/bajacalifornia/Cadetes-Ejercito-integrarse-Policia-Municipal_o_272972969.html [consulta: 30/II/2020].

McGrath, Robert

2013 "The Rise and Fall of Radical Civil Service Reform in the U.S. States", Public Administration 73(4), pp. 638-649, https://doi.org/IO.IIII/ puar.12075

Merino, Mauricio

2010 Ética Pública, Biblioteca Básica de Administración Pública, México, EAPDF/Siglo Xxi Editores.

Merino, Mauricio

20 II "Sobre la Evaluación de Políticas Públicas" en Roberto Salcedo, Evaluación de Políticas Públicas, México, Siglo xxi Editores.

Merino, Mauricio

2013a "La captura de los puestos públicos", Revista Mexicana de Ciencias Politicas y Sociales, 219, pp. 135-156, https://doi.org/10.1016/So1851918(13)72306-7

Merino, Mauricio

$2013 \mathrm{~b}$ Ensayo sobre la intervención del Estado en la solución de problemas públicos, México, CIDE. 
Meyer, Maureen

2014 Mexico's Police: Many Reforms, Little Progress, wola, mayo, https:// www.wola.org/sites/default/files/Mexicos\%2oPolice.pdf [consulta: $30 / 1 \mathrm{II} / 2020]$.

Moloeznik, Marcos Pablo y María Eugenia Suárez de Garay

2013 "De la estrategia en el modo de acción directo en el ámbito de la seguridad ciudadana. Justiciabarómetro en la policía municipal de Ciudad Juárez", Gestión y Política Pública, pp. 83-126.

Munguía, Karen

2017 "Suman 74 policías estatales dados de baja durante la actual administración: Ssc", Códice Informativo. https://codiceinformativo.com/2017/04/ suman-74-policias-estatales-dados-de-baja-durante-la-actual-administracion-ssc/ [consulta: 30/II/2020].

Nieto, Fernando, Liesbet Heyse, María del Carmen Pardo y Rafael Wittek

2014 "Building Enforcement Capacityः evidence from the Mexican Civil Service Reform," Public Administration and Development, 34(5), pp. 389-405, https://doi.org/I0.I002/pad.I70I

Noticias Voz e Imagen

2016 "Crece inconformidad de Policías Municipales", 20 mayo http://www. nvinoticias.com/nota/ı2119/crece-inconformidad-de-policias-municipales [consulta: $30 / \mathrm{II} / 2020$ ].

Oppenheimer, Andrés

2015 "Las engañosas estadísticas de la violencia”, El Mundo, i5 mayo. http://www.elmundo.es/internacional/2015/05/15/5554bda2268e3e282c8b45ar.html [consulta: 30/II/2020].

Peña Nieto, Enrique

2014 Iniciativa de Decreto por el que se reforman los artículos 21, 73, 104, 105, 115, 116 y 123 de la Constitución Politica de los Estados Unidos Mexicanos, I de diciembre. http://www.senado.gob.mx/comisiones/justicia/docs/ Audiencias_Seg_Justicia/Iniciativa_Poder_Ejecutivo.pdf [consulta: $30 / \mathrm{II} / 2020]$.

\section{Periódico Central}

2017 “El colmo! Policía municipal y su esposa asaltan Oxxo en Bosques de Manzanilla; vecinos los golpean", 20/07. http://www.periodicocentral. $\mathrm{mx} / 2017 /$ pagina-negra/crimen-y-castigo/item/12268-hasta-en-parejavecinos-de-bosques-de-manzanilla-golpean-a-policia-que-asalto-unoxxo-junto-con-su-esposa [consulta: 30/II/2020]. 
Pollitt, Christopher y Geert Bouckaert 200I Public Reform Management, Oxford, Oxford University Press.

Pressman, Jeffrey y Aaron Wildavsky 1998 Implementación. Cómo grandes expectativas concebidas en Washington se frustran en Oakland, México, FCE.

Proceso

2017 "Detienen a cinco policías de Atizapán acusados de secuestro", 20/07, http://www.proceso.com.mx/495704/detienen-a-cinco-policias-atizapan-acusados-secuestro [consulta: 30/II/2020].

Radio Fórmula

2017 "Detienen por secuestro al jefe de policía de Madera, Chihuahua", II/o7, http://www.radioformula.com.mx/notas.asp? $\mathrm{Idn}=697663 \&$ i$\mathrm{dFC}=2017$ [consulta: $30 / \mathrm{II} / 2020$ ].

Reza, Gloria

2013 "Policías reprobados lanzan un sos al Congreso", Proceso, 26/oI, https:// data.proceso.com.mx/?p=331727 [consulta: $30 / \mathrm{II} / 2020$ ].

Rivas, Francisco

2016 "Carta a Osorio Chong". Observatorio Nacional Ciudadano, 2I/O4. https://onc.org.mx/carta-al-secretario-de-gobernacin-miguel-ngel-osorio-chong [consulta: 30/II/2020].

Sabet, Daniel

2013 "El problema de la gobernanza municipal: el reto de la reforma policial Salmerón, Argenis en los municipios de México", Foro Internacional, 53(2), pp. 253-280.

2016 "Minimiza de nuevo Sedano la violencia;"la hay en todas las ciudades del mundo", dice", El Sur, 18/05/16, http://suracapulco.mx/4/minimiza-de-nuevo-sedano-la-violencia-la-hay-en-todas-las-ciudades-delmundo-dice/ [consulta: 18/08/2016].

Subsecretariado Ejecutivo del Sistema Nacional de Seguridad Pública (sesnsp) 201 Subsidio para la Seguridad Pública Municipal (subSemun), http://www. secretariadoejecutivo.gob.mx/work/models/SecretariadoEjecutivo/ Resource/776/I/images/subsemun.pdf [consulta: 30/II/2020].

SESNSP

2016 Ejes Estratégicos y Programas con Prioridad Nacional, Secretaría de Gobernación, I5/or http://www.secretariadoejecutivo.gob.mx/docs/pdfs/ normateca/Reglamentos/DocumentoI.pdf [consulta: 30/II/2020]. 


\section{Símerman, Francisco}

2016 "Pretende Aragón Roldán imponer a su "Guarura" como Comisario de la Policía Municipal”. Enlace de la Costa, 05/04, http://www.enlacedelacosta.com/index.php/en/regional/84-mixtepec/6698-pretende-aragon-roldan-imponer-a-su-guarura-como-comisario-de-la-policia-municipal [consulta: $18 / 08 / 2020$ ].

SinEmbargo

2020 "Policía municipal de Tijuana implicado en secuestro es detenido en horas de servicio", Io/Io/2019, https://www.sinembargo.mx/IO-IO2019/36594IO [consulta: 30/II/2020].

Sosa Altamira, William

2014 Punto de acuerdo del Grupo Parlamentario del PRI, Gaceta Parlamentaria, 3995-VI, 03/04. http://gaceta.diputados.gob.mx/Black/Gaceta/ Anteriores/62/20I4/abr/20I40403-vi/Proposicion-8.html [consulta: $30 / \mathrm{II} / 2020]$.

Sundell, Anders

2014 "Are formal civil service examinations the most meritocratic way to recruit civil servants? Not in all countries", Public Administration, 92(2), pp. 440-457. https://doi.org/IO.IIII/padm.I2077

Swenson, Joy y Fred Casmir

1998 "The impact of culture-sameness, gender, foreign travel, and academic background on the ability to interpret facial expression of emotion in others", Communication Quarterly, 46(2), pp. 214-223. https://doi. org/IO.I080/0I463379809370096

Székely Pardo, Miguel

2012 "Políticas de Profesionalización Policial en México: Avances y perspectivas", en Székely Pardo, M. (coord.), Sistema Integral de Desarrollo Policial: La construcción de una policía profesional en México, México, CIES.

Tello, Nelia

2013 "Cultura de la legalidad de los policías municipales de Cuernavaca", Gestión y Política Pública, pp. 289-311.

Tsebelis, George

1995 "Decision Making in Political Systems: Veto Players in Presidentialism, Parliamentarism, Multicameralism and Multipartyism”, British Journal of Political Science, 25(3), pp. 289-325. https://doi.org/IO.IOI7/ Sooo7123400007225 
Weyland, Kurt

2008 “Toward A New Theory of Institutional Change," World Politics, 6o(2), pp. 28I-314, https://doi.org/I0.1353/wp.0.0013

Withers, George, Lucila Santos y Adam Isacson

2010 Preach What You Practice: The Separation of Military and Police Roles in the Americas, http://www.wola.org/publications/preach_what_you_ practice_the_separation_of_police_and_military_roles_in_the_americas [consulta: $30 / \mathrm{II} / 2020$ ].

\section{ZonaFranca}

2014 "Detienen a policía Municipal que transportaba combustible robado en Salamanca", http://zonafranca.mx/detienen-a-policia-municipal-que-transportaba-combustible-robado-en-salamanca/ [consulta: $30 / 11 / 2020]$.

José Manuel Heredia González

Doctor en Políticas Públicas por el Centro de Investigación y Docencia Económicas; maestro en Estudios de Seguridad con especialidad en Operaciones de Inteligencia por la Universidad de Georgetown, Washington, D.C.; licenciado en Ciencia Política y Relaciones Internacionales por el Centro de Investigación y Docencia Económicas. Sus líneas de investigación incluyen profesionalización administrativa, tendencias en la denuncia del delito en México y la participación de policías en delitos de bajo y alto impacto.

Citar como: José Manuel Heredia González (202I), "Obstáculos prácticos, políticos y administrativos para la profesionalización de las policías municipales mexicanas", Iztapalapa. Revista de Ciencias Sociales y Humanidades, núm. 90, año 42, enero-junio de 202I, ISSN: 2007-9176; pp. 8I-II8. Disponible en $<$ http://revistaiztapalapa.izt.uam.mx/index.php/izt/issue/archive $>$. 